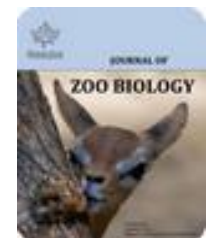

Available Online at EScience Press

Journal of Zoo Biology

ISSN: 2706-9761 (Online), 2706-9753 (Print)

https://esciencepress.net/journals/JZB

\title{
CLINICAL MANAGEMENT OF A COMPLETE GASTROINTESTINAL OBSTRUCTION AND ILEUS IN A GERIATRIC FEMALE ASIAN ELEPHANT (ELEPHAS MAXIMUS)
}

\author{
aWhitney Greene, bSusan Mikota, cJean Pitcairn, dMichael Ryer \\ a Buttonwood Park Zoo, 425 Hawthorn Street, New Bedford, MA 02740, USA. \\ ${ }^{b}$ Elephant Care International, 166 Limo View Lane, Hohenwald, TN 38462, USA. \\ ${ }^{c}$ Chase Farm Veterinary Hospital, 35 Ventura Drive, North Dartmouth, MA 02747, USA. \\ ${ }^{d}$ New England Animal Medical Center, 595 W Center Street, West Bridgewater MA 02379, USA.
}

*Corresponding Author Email: wgreenedvm@gmail.com Tel: +1-508-525-0788

\section{A B S T R A C T}

A 58-year-old female Asian elephant (Elephas maximus) was diagnosed with a complete gastrointestinal obstruction and accompanying ileus. She was anorexic for five days, did not pass stool for seven days, and her abdomen was visibly distended. Treatment included: rectal and IV fluids; oral and rectal stool softeners; mineral oil; ketoprofen; laser acupuncture; and fecal transfaunation. The blockage was successfully expelled after seven days yielding a large bolus weighing $52 \mathrm{~kg}$ followed shortly by another $45 \mathrm{~kg}$ of feces.

Keywords: Acupuncture, Asian elephant, colic, Elephas maximus, fecal transfaunation, gastrointestinal, geriatric, ileus, impaction.

\section{STATEMENT OF THE PROBLEM}

A 58-year-old female Asian elephant (Elephas maximus) presented for constipation, anorexia, and abdominal distension. She did not defecate for seven days and exhibited signs of pain such as head pressing, stretching, and pushing against the wall. Chronic arthritis was managed by the administration of ibuprofen $6.6 \mathrm{mg} / \mathrm{kg}$ PO q $12 \mathrm{hr}$, (Bechert \& Christensen, 2007), 250 g of Glycoflex PO daily (FoodScience Corporation, VetriScience Laboratories, Essex Junction, Vermont, 05452, USA), and laser therapy of the right elbow. Laser therapy was performed three times a week using three joules for five min administered at four sites per session. Her diet consisted of timothy hay, browse, a variety of produce, and Mazuri Elephant Supplement (PMI Nutrition, MAZURI, Richmond, IN, USA).

\section{DESCRIPTION OF THE PROCESS}

On physical examination, the abdomen was distended bilaterally and inspection of the oral cavity suggested her last set of molars were in wear. Differential diagnoses included partial or complete hay or sand impaction, bacterial enteritis, volvulus, foreign body ingestion, salmonellosis, and neoplasia, especially uterine leiomyomas which are common in older elephant cows.

The initial workup included a complete blood count (CBC), serum chemistries, urinalysis, salmonella PCR, and rectal fecal culture. Packed cell volume (PCV), reported as the best prognostic indicator for colic in elephants (Allwin, Kalaignan, \& Senthil, 2015) and horses (Parry, Anderson, \& Gay, 1983) was performed once or twice daily and was also used to monitor hydration. Blood was collected from the auricular veins with the elephant in lateral recumbency. Hematologic and urinalysis values remained within normal limits over the course of the seven day episode.

Working on a presumptive diagnosis of bowel obstruction, initial management consisted of warm water enemas, three doses of flunixin meglumine (Banamine; Merck Animal Health, Germany, Intervet International BV) $1 \mathrm{mg} / \mathrm{kg}$ IM q $12 \mathrm{hr}$ (Kottwitz et al., 2016), and offering oral fluids (variety of fruit juices and oral electrolyte drinks). Two doses of butorphanol tartrate (Torbugesic, Pfizer Inc, New York, NY 10017, USA) 0.015 $\mathrm{mg} / \mathrm{kg}$ SQ (Ingram, Isaza, Koch, \& Hunter, 2005) were administered, however, the elephant was observed to be 
more lethargic and continued to exhibit signs of pain, therefore analgesia treatment was changed to ketoprofen (Zoetis; Kalamazoo, MI 49007, USA). For the first four days, a dose of $2 \mathrm{mg} / \mathrm{kg}$ IV q $24 \mathrm{hr}$ was administered, which was then decreased to $1 \mathrm{mg} / \mathrm{kg}$ for two doses, with the final dose of $1 \mathrm{mg} / \mathrm{kg}$ being administered at an interval of $48 \mathrm{hr}$ (Hunter, Isaza, \& Koch, 2003). Ceftiofur sodium (Naxcel; Zoetis, Kalamazoo, MI 49007, USA), $1.1 \mathrm{mg} / \mathrm{kg}$ IM q $24 \mathrm{hr}$ (Dumonceaux, Isaza, Koch, \& Hunter, 2005) was given for seven days to prevent infection from a potential compromised bowel wall.

Gastrointestinal sounds and heart rate are the most important primary measurements for distinguishing between simple and critical colic in horses (Jennings, Curtis, Burford, \& Freeman, 2014). In our patient, the heart rate was difficult to auscultate and the auricular vein could not be easily assessed due to a previous injury to the ears. Gastrointestinal sounds were auscultated and the animal's girth was measured daily to monitor the extent of abdominal distension. Two chalk marks were made on the dorsal and ventral abdomen as measuring points for consistency. Gastrointestinal sounds were absent initially but were heard beginning on the fourth day.

The animal refused oral fluids during the initial $24 \mathrm{hr}$ period, thus an $18 \mathrm{ga}, 1 \frac{1 / 4}{4}$ inch catheter (Terumo Superflo I.V. catheter Somerset, NJ, 08873. USA) was placed in the right auricular vein and $15 \mathrm{~L}$ of lactated ringers solution (LRS, Hospira, Inc., Lake Forest, Illinois 60045 USA) was administered. Despite the successful placement of the catheter, it became clotted and bent and required replacement to facilitate administration of an additional 15 L of LRS. Monitoring of the PCV showed that the elephant was maintaining adequate hydration (PCV 3844) from retention of enema fluids and the rectal administration of $15 \mathrm{~L}$ of LRS (using a standard large animal stomach pump), therefore IV fluids were discontinued. Enemas and rectal fluid administration were performed two-to-three times daily. Enemas were initially administered for 10-20 min using a garden hose attached to the water supply in the barn. On the fourth day, two 208 liter barrels of water were set up, the temperature was maintained at $99^{\circ} \mathrm{F}$, and the enemas were administered using a 4,542 liter per hr commercial pond (waterfall) pump (Smartpond, West Palm Beach, FL USA). Fluids returned from enemas administered on days 1-5 were consistently clear, with an occasional brown hue or a single piece of straw. Although these initial enemas were not helping to dislodge the impaction, the retained fluid maintained the PCV at 38-44 during the period when the elephant refused to drink. Following the enema sessions, the elephant was walked around her exhibit and encouraged to swim in the exhibit pool. During the occasions when fluids were not given following the enema, the rectum was cleared of excess water and mineral oil (VEDCO INC, St. Joseph, MO 60507, USA) was administered using the large animal stomach pump or bisacodyl suppositories (Dulcolax, Boehringer Ingelheim Pharmaceuticals Inc, Ridgefield, CT 06877 USA) $400 \mathrm{mg}$ ( $40 \times 10 \mathrm{mg}$ tablets) were manually inserted rectally as far cranial as possible (Silva \& Dangolla, 2006). On the evening of the fifth day, the animal began eating and $300 \mathrm{mg}$ (5 mg tablets) of bisacodyl (Dulcolax, Boehringer Ingelheim Pharmaceuticals Inc, Ridgefield, CT 06877, USA) was administered in focaccia bread and continued PO q $12 \mathrm{hr}$ for five days. Once the elephant's appetite improved, $75 \mathrm{~g}$ of psyllium (Metamucil, Proctor and Gamble, Cincinnati, OH 45202, USA) was mixed into $.45 \mathrm{~kg}$ of wet bran with strawberry syrup and fed in round balls, approximately two tablespoons each.

Laser acupuncture was initiated on day 4 to address ileus, pain, and to help stimulate motility and the function of the gastrointestinal tract. The following acupoints were used for treatment: BL-40, GB-24, GB-34, LI-11, LIV-13, LIV-14, ST-25, ST-36, ST-37, ST-38, ST-40, ST-45, and TH-6. The anatomical locations of the points were determined using a published elephant acupuncture chart (Mikota, 2017) and the points selected were based on their association with gastrointestinal function in equine gastrointestinal disorders (Dill \& Bierman, 2001; Fleming, 2001). Four points were stimulated per session with three joules for five min sessions using a LuminexVet laser unit (Respond Systems Incorporated, Branford, CT, 06045 USA).

\section{DEMONSTRATION OF EFFICACY}

On the sixth day, a bolus was finally palpated rectally. The bolus was extremely firm and large and could not be dislodged. Small portions of the bolus could be manually removed, but it was impossible to remove the entire bolus in this manner. A 190-liter warm water enema was administered caudal to the bolus while we attempted to insert the hose directly into the bolus. Bisacodyl suppositories ( $400 \mathrm{mg}$ ) were inserted manually into the bolus and around the periphery. Thirty-eight liters of mineral oil and four liters of warm water mixed with $47 \mathrm{~g}$ of dioctly sodium sulfosuccinate (Veterinary Surfactant (DSS) Vedco Inc, St. Joseph, MO 64507, USA) were administered per rectum. Approximately one-third of the 
Technical Report

mixture was expelled, but the remainder was retained overnight.

The following morning, the enema was repeated along with the bisacodyl suppositories. The bolus was more caudal and softer than the previous day. The hose was advanced past the bolus allowing enema fluid to be deposited cranial to the mass and into the bolus. A combination of mineral oil ( $485 \mathrm{~mL}$ ) and DSS (28 g) was administered directly into the bolus and around the perimeter, followed by $15 \mathrm{~L}$ of warm LRS administered per rectum. The elephant was released into the exhibit and approximately five $\mathrm{hr}$ later, passed a $52 \mathrm{~kg}$ bolus. This was followed shortly by another $45 \mathrm{~kg}$ of feces.

Psyllium was continued for ten days followed by a twice monthly maintenance dose. On days 8 and 10, quartered oranges were fed to track transit time by observing feces for undigested orange peels. On day 9, a fecal transfaunation was performed using feces from her exhibit mate according to methods recommended by Dr. T.J. Divers (Mullen, Yasuda, Divers, \& Weese, 2016). Fecal transfaunation was performed to correct potential microbial imbalances that may have resulted from the prolonged ileus. Four kg of feces were manually mixed with $1.6 \mathrm{~L}$ of $0.9 \% \mathrm{NaCl}$ and 1.9 liters of warm water and maintained at $99^{\circ} \mathrm{F}$. The mixture was strained through a sieve to remove large pieces and the resulting liquid was used to fill $5 \mathrm{~mL}$ (size 12) gel capsules (Torpac Inc. Fairfield, NJ 07004, USA). The fecal capsules were administered rectally (nine capsules) and orally (12 capsules in focaccia bread). The fecal transfaunation was performed once, approximately $48 \mathrm{hr}$ following the first successful stool.

Elephants are hindgut fermenters and spend on average 16-20 hr per day eating (Clauss, Loehlein, Kienzle, \& Wiesner, 2003; Dumonceaux, 2006). Asian elephants drink 200-255 L of water per day and as much as 50-60 L at one time (Cheeran, 2002). The average cecal volume in 10 adult elephants was $90.1+/-10.1$ liters and the average colon volume in a single adult animal was $329+$ +- 30.1 liters (Van Hoven, Prine, \& Lankhorst, 1981). Small intestine length ranges from 11-21.6 $\mathrm{m}$ and large intestine length ranges from 6-12.8 m (Mikota, Sargent, \& Ranglack, 1994). Gastrointestinal transit time is between $21-55 \mathrm{hr}$ in captive Asian elephants (Dierenfeld, 2006). The elephant in the present case had a transit time of approximately $60 \mathrm{hr}$ once she regained normal gastric motility.

Several dietary and husbandry changes were initiated since the incident. The animal receives $100 \%$ chopped hay. She was transitioned from Mazuri to Equine Senior (Purina Animal Nutrition LLC, Minneapolis, MN, USA) with daily additions of $11 \mathrm{cc}(5,500 \mathrm{IU})$ Vitamin E (Stuart Products, Bedford, TX 76022, USA), $4.4 \mathrm{~kg}$ of beet pulp, and $2.2 \mathrm{~kg}$ of bran to offer a more easily digestible diet. The animal is offered $100 \%$ cooked vegetables and fruit, and fruit and vegetable smoothies are offered as enrichment. Additionally, she has been maintained on a six-day a week laser acupuncture treatment schedule alternating between points to support her gastrointestinal system.

The presumptive diagnosis for this case was complete gastrointestinal impaction that prevented the elephant from defecating for over a week. The definitive cause of the impaction was not determined, but was likely multifactorial given the elephant's advanced age. These include: poor mastication due to worn teeth; digestive issues such as decreased motility, secretion, and absorption; and environmental factors. The possibility of an underlying neoplastic condition (especially of the uterus) could not be ruled out. Through medical management and husbandry, the animal successfully cleared the impaction and normal gastrointestinal function was restored. This report highlights the need for dietary, medical, and husbandry related modifications in geriatric animals and how such treatments often require innovation. Use of alternative treatments, such as acupuncture and fecal transfaunation in elephants is limited, but these treatments were successful in the present case and these procedures warrant further exploration.

\section{ACKNOWLEDGEMENTS}

The authors gratefully acknowledge the dedicated care of the elephant keepers at Buttonwood Park Zoo who provided 24/7 care and the support of general curator, Shara Crook, and zoo director, Keith Lovett. We additionally thank Not Your Average Joe's, a local restaurant, for their generous donation of many loaves of focaccia bread.

In addition, these veterinarians provided input on this case: Dr. Michele Miller (AZA Elephant TAG), Dr. Jeff Wyatt (Seneca Park Zoo, University of Rochester), Dr. Jim Oosterhuis, and Dr. Jeff Zuba (San Diego Zoo Global), Dr. Jacob Cheeran (Cheerans Lab Ltd, India), Dr. Huisheng Xie (Chi Institute), Dr. Maria Spriggs (Busch Gardens Tampa), Dr. Jen Flower and Dr. Allison Tuttle (Mystic Aquarium), Dr. Thomas Divers (Cornell University), and Dr. Ellen Dierenfeld., LLC). 


\section{CONFLICT OF INTEREST}

The authors declare no conflicts of interest.

\section{REFERENCES}

Allwin, B., P.A. Kalaignan and N.R. Senthil. 2015. Haematobiochemical parameters as prognostic indicators in elephant colic. Journal of Veterinary Medicine and Animal Health, 7, 169-172.

Bechert, U., and J.M. Christensen. 2007. Pharmacokinetics of orally administered ibuprofen in African and Asian elephants (Loxodonta Africana and Elephas maximus). Journal of Zoo and Wildlife Medicine, 38, 258-268.

Cheeran, J.V. 2002. Elephant facts. Indian Veterinary Journal, 7, 12-14.

Clauss, M., W. Loehlein, E. Kienzle and H. Wiesner. 2003. Studies on feed digestibilities in captive Asian elephants (Elephas maximus). Journal of Animal Physiology and Animal Nutrition, 87, 160-173.

Dierenfeld, E.S. 2006. Nutrition. In M.E. Fowler \&. S.K. Mikota (Eds.), Biology, medicine, and surgery of elephants (pp. 57-65). Oxford, United Kingdom: Blackwell Publishing Ltd.

Dill, S.G., and N. Bierman. 2001. Acupuncture for gastrointestinal disorders. In A.M. Schoen, (Ed.), Veterinary acupuncture (pp. 239-260). St. Louis, Missouri: Mosby.

Dumonceaux, G.A. 2006. Digestive System. In M.E. Fowler \& S.K. Mikota (Eds.), Biology, medicine, and surgery of elephants (pp. 299-307). Oxford, United Kingdom: Blackwell Publishing Ltd.

Dumonceaux, G., R. Isaza, D.E. Koch and R.P. Hunter. 2005. Pharmacokinetics and i.m. bioavailability of ceftiofur in Asian elephants (Elephas maximus). Journal of Veterinary Pharmacology and Therapeutics, 28, 441-446.

Fleming, P. 2001. Treatment of equine gastrointestinal disease with acupuncture. In A.M. Schoen (Ed.), Veterinary acupuncture (pp. 475-480). St. Louis, Missouri: Mosby.

Hunter, R.P., R. Isaza and D.E. Koch. 2003. Oral bioavailability and pharmacokinetic characteristics of ketoprofen enantiomers after oral and intravenous administration in Asian elephants (Elephas maximus). American Journal of Veterinary Research, 64, 109-114.

Ingram, L.M., R. Isaza, D.E. Koch and R.P. Hunter. 2005. Pharmacokinetics of intravenous and intramuscular butorphanol in Asian elephants (Elephas maximus). Proceedings of the American Association of Zoo Veterinarians (AAZV), American Association of Wildlife Veterinarians (AAWV), and Association of Zoos and Aquariums (AZA) Nutrition Advisory Group, 2005, 70-71.

Jennings, K.M., L. Curtis, J.H. Burford and S.L. Freeman. 2014. Prospective survey of veterinary practitioners' primary assessment of equine colic: clinical features, diagnoses, and treatment of 120 cases of large colon impaction. BMC Veterinary Research, 10 (Suppl 1), 52.

Kottwitz, J., M. Booth, R. Harmon, S.B. Citino, J.R. Zuba and D.M. Boothe. 2016. Results of the megavertebrate analgesia survey: elephants and rhino. Journal of Zoo and Wildlife Medicine, 47, 301-310.

Mikota, S.K. 2017. Acupuncture in elephants. In H. Xie \& H. Ramirez (Eds.), Practical guide to traditional Chinese veterinary medicine Volume 4. Exotic Animals (pp. 297-323). Reddick, Florida: Chi Institute Press.

Mikota, S.K., E.L. Sargent and G.S. Ranglack. 1994. Medical management of the elephant (pp. 95-106). West Bloomfield Michigan: Indira Publishing House.

Mullen, K.R., K. Yasuda, T.J. Divers and J.S. Weese. 2016. Equine faecal microbiota transplant: current knowledge, proposed guidelines and future directions. Equine Veterinary Education, 30, 151-160.

Parry, B.W., G.A. Anderson and C.C. Gay. 1983. Prognosis in equine colic: a study of individual variables used in case assessment. Journal of Equine Veterinary Science, 15, 337-344.

Silva, I., A. Dangolla. 2006. Veterinary problems of geographical concern Section VIII: Sri Lanka. In M.E. Fowler \& S.K. Mikota (Eds.), Biology, medicine, and surgery of elephants (pp. 468-473). Oxford, United Kingdom: Blackwell Publishing Ltd.

Van-Hoven, W., R.A. Prine and A. Lankhorst. 1981. Fermentative digestion in the African elephant. South African Journal of Wildlife Research, 11, 78-86. 
Publisher's note: EScience Press remains neutral with regard to jurisdictional claims in published maps and institutional affiliations.

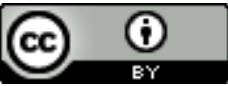

Open Access This article is licensed under a Creative Commons Attribution 4.0 International License, which permits use, sharing, adaptation, distribution and reproduction in any medium or format, as long as you give appropriate credit to the original author(s) and the source, provide a link to the Creative Commons license and indicate if changes were made. The images or other third-party material in this article are included in the article's Creative Commons license, unless indicated otherwise in a credit line to the material. If material is not included in the article's Creative Commons license and your intended use is not permitted by statutory regulation or exceeds the permitted use, you will need to obtain permission directly from the copyright holder. To view a copy of this license, visit http://creativecommons.org/licenses/by/4.0/.

(C) The Author(s) 2019 . 